\title{
The New Approach to Wilderness Preservation through Benefit-Cost Analysis
}

\author{
RIChaRd C. PorTeR ${ }^{1}$ \\ Department of Economics, University of Michigan, \\ Ann Arbor, Michigan 48109
}

Received April 16, 1979; revised August 1, 1980

\begin{abstract}
Over the last 15 years, economists of Resources for the Future led by John Krutilla have been developing a new approach to wilderness preservation. This paper offers a concise exposition of their approach and adds a few new steps. The basic ingredient of the new approach is a perception of declining net benefits of wilderness development and rising net benefits of wilderness preservation over time. These alter the entire shape of the benefit-cost analysis of potential development. The new steps involve reversibility, postponability, and recognition of multiple interest rates.

Do economists know about lupines?

Aldo Leopold
\end{abstract}

Over the last 15 years, economists of Resources for the Future led by John Krutilla have been developing a new approach to wilderness preservation. They reject the narrowly viewed profitability of a project as an adequate criterion for the acceptability of the project when it destroys wilderness values, insisting that the current and future value to society of the preserved wilderness area be explicitly considered.2 This idea of measuring the opportunity cost of wilderness has not been without opponents, even from within the preservationist camp. ${ }^{3}$ But they have managed, in a decade, to add a strong economic foundation to the emotional and philosophical defense of wilderness preservation.

The purpose of this paper is to offer a concise exposition of their approach and to add a few new steps. In Section I, the basic contribution of the new approach is explained, in terms of three new parameters that are introduced into the development decision. In Section II, the precise way in which these parameters affect the decision is examined. In Section III, the relationship between the new approach and the timing of irreversible development decisions is developed. In Section IV, some of the problems of estimation of the newly introduced parameters are discussed. In Section V, the implications for the analysis are explored for a world where more than one interest rate is observed; specifically, the new approach is extended to consider two discount rates, a rate of marginal capital productivity and a rate of time preference. Criteria are derived, in Section VI, for reversible wilderness developments and in Section VII, for postponement of exhaustible wilderness developments. A brief summary is offered in Section VIII.

${ }^{1}$ I am indebted for helpful comments on an earlier draft to E. M. Gramlich, J. V. Krutilla, P. Portney, H. R. Varian, and E. A. Wilman.

${ }^{2}$ This approach, of course, examines social rather than commercial profitability.

${ }^{3}$ For example, S. A. Cain: "I would not, in defending the wilderness, try to compete with the dollar values of the marketplace... One believes in wilderness, or he doesn't." [9, p. 19]. 
This "new approach" is intended to be operational-indeed, it has been developed in the course of a series of specific wilderness development battles ${ }^{4}$-and, as a result, two important aspects of recent wilderness discussions are largely ignored. One, the general-equilibrium approach treats wilderness as an irreversibly exhaustible stock and examines the individual development project as an incremental decision; the "new approach" concentrates, in traditional benefit-cost fashion, on the project itself, although the values of the exogenous parameters reflect an implicit view of the general-equilibrium system. And two, decision making under uncertainty intrudes critically when an irreversible development decision is considered where the foregone future wilderness values are currently unclear; ${ }^{5}$ benefit-cost analysis, in this area as elsewhere, is not yet equipped to handle uncertainty explicitly and comfortably.

\section{THE NEW APPROACH}

Traditionally, the evaluation of a proposed project to introduce development into a wilderness area has considered an unpriced preservation alternative as a situation of neither benefit nor cost. The question asked was simply whether the anticipated flow of benefits derived from development exceeded the flow of costs (both in a present value sense). For example, consider a development project that initially costs $\$ 1$ and yields an instantaneous flow of real net social benefits of $\$ D$ ( $D$ for Development) forever after. The traditional calculation of the present value $(P V)$ of the project now (i.e., at $t=0$ ), using a social discount rate of $i$, is

$$
P V=-1+\int_{t=0}^{\infty} D e^{-i t} d t=-1+\frac{D}{i}
$$

This relationship between $P V$ and $i$ is shown in Fig. 1. Clearly, the project passes the $P V$ test if the flow of net benefits $(D)$ exceeds the social discount rate $(i)$.

Under the new approach, two additional elements are considered in this present value calculation. First, the development of a wilderness area destroys any benefits society might have derived from the continued existence of the area in an undisturbed state. The present value calculation must then include, as a cost of development, the real, net foregone flow of benefits of preservation, $\$ P$ ( $P$ for Preservation). The preservation benefits include not only those that accrue to users of the wilderness but also any existence, option, and "quasi-option" values. Some of these values inevitably involve uncertainty, but the benefit-cost analysis typically assumes that all variables are known for certain, or that the use of expected values does not introduce important error. The $P V$ becomes;

$$
P V=-1+\frac{D}{i}-\int_{t=0}^{\infty} P e^{-i t} d t=-1+\frac{D}{i}-\frac{P}{i}
$$

This relationship between $P V$ and $i$ is exactly the same as that shown in Fig. 1 with one change-the hyperbola now crosses the $i$-axis at $(D-P)$ rather than at $D$. Thus, the development project passes the $P V$ test only if its flow of net benefits $(D)$

\footnotetext{
${ }^{4}$ Reference [25, and the works cited therein].

${ }^{5}$ Both of these concerns are prominent in Arrow's writings-see [2-4]. See also the literature on "option values" [11, and the works cited therein].
} 


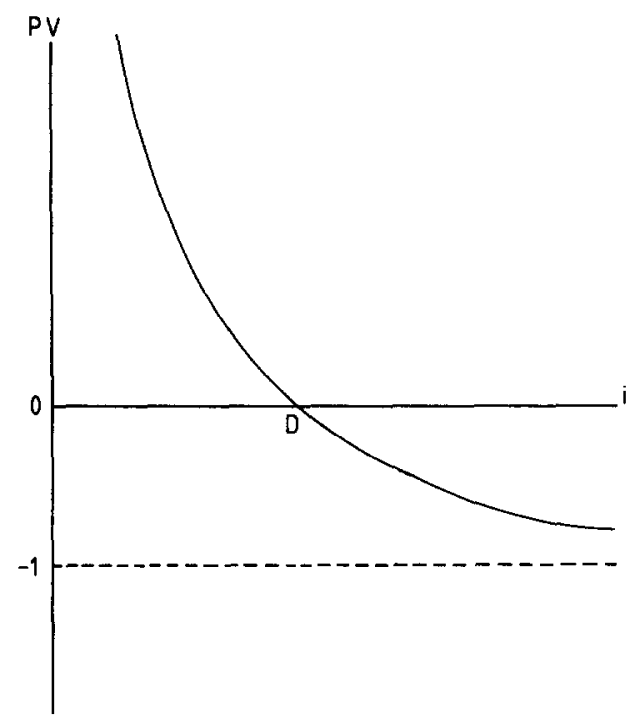

Figure 1

exceeds the sum of the discount rate $(i)$ and the flow of net benefits with preservation $(P)$. The criterion for acceptance of the development project has been made more stringent, $D>i+P$ rather than $D>i$.

The second element of the new approach involves the time paths of the flows of net benefits from development and from preservation. A fundamental asymmetry is perceived in these time paths. Development of wilderness is seen as the extraction or production of a physical product which exhaustion or technological advance will probably render less valuable as time passes. Wilderness preservation, on the other hand, is seen as the provision of services with - by the nature of wilderness-a quite inelastic supply curve that is shifting steadily inward as a result of encroachment and congestion. ${ }^{6}$ While these are plausible, and to some convincing, arguments, the real issue is whether they are empirically accurate in each specific application. Since I am here interested in exploring the conceptual implications of this asymmetry, I will not question these general perceptions.

Consider an exponential process whereby the preservation benefits at time $t\left(P_{t}\right)$ grow at rate $\rho$ from an initial rate of $P$,

$$
P_{t}=P e^{\rho t},
$$

and the development benefits at time $t\left(D_{t}\right)$ decline at rate $\delta$ from an initial rate of $D$,

$$
D_{t}=D e^{-\delta t} \text {. }
$$

The $P V$ becomes $^{7}$

$$
\begin{aligned}
P V & =-1+\int_{t=0}^{\infty} D e^{-(i+\delta) t} d t-\int_{t=0}^{\infty} P e^{-(i-\rho) t} d t, \\
& =-1+\frac{D}{i+\delta}-\frac{P}{i-\rho} .
\end{aligned}
$$

${ }^{6}$ Note the implicit general-equilibrium system.

${ }^{7}$ Assuming, as we must if $P V$ is to be finite, that $i>\rho$. 


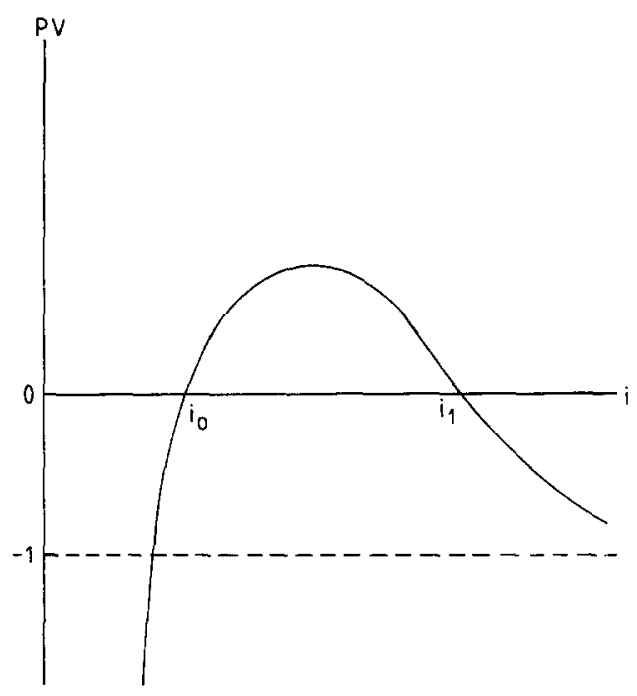

FIGURE 2

This $P V$, Eq. (5), represents more change than at first meets the eye. Whereas the introduction of $P$ shifted to the right the hyperbola that related $P V$ to $i$ (as in Fig. 1), this second change, the introduction of $\rho$ and $\delta$, fundamentally alters the shape of the relationship of $P V$ and $i$. As Fig. 2 shows, for a development project to pass the $P V$ test, the rate of discount (i) must lie in a particular range, i.e., between $i_{0}$ and $i_{1}{ }^{8}$ The reason for this double boundary on $i$ is easily seen. For sufficiently high rates of discount (i.e., for $i>i_{1}$ in Fig. 2), the development project fails for the traditional reason, that the benefits it yields ( $D$ or $D_{t}$ ) are too heavily discounted to offset the initial cost of the project. And for sufficiently low rates of discount (i.e., for $i<i_{0}$ in Fig. 2), the exponentially growing benefits of preservation $\left(P_{t}\right)$ are so little discounted that their perpetual loss becomes too great a cost for the development project to shoulder. Thus, for sufficiently low or sufficiently high discount rates, the development project will fail its $P V$ test.

In short, the preservationists' new approach narrows the range of social discount rates for which a development project will appear profitable. The precise way in which the new parameters $(P, \rho$, and $\delta)$ affect the $P V$ test is illuminating and is examined in the next section.

\section{THE NEW PARAMETERS}

The new approach to any controversy between preservation and development of wilderness areas insists that three new concepts be introduced into the analysis, and these concepts are captured, in the illustrative stereotypical development project of Section I (with PV Eq. (5)), by the three new parameters: $P$, the current flow of real net benefits attributable to the area in its current natural state; $\rho$, the anticipated

\footnotetext{
${ }^{8}$ Figure 2 is drawn for a project for which $\sqrt{D}>\sqrt{P}+\sqrt{\delta+\rho}$ (this inequality is developed and discussed in Section II).
} 


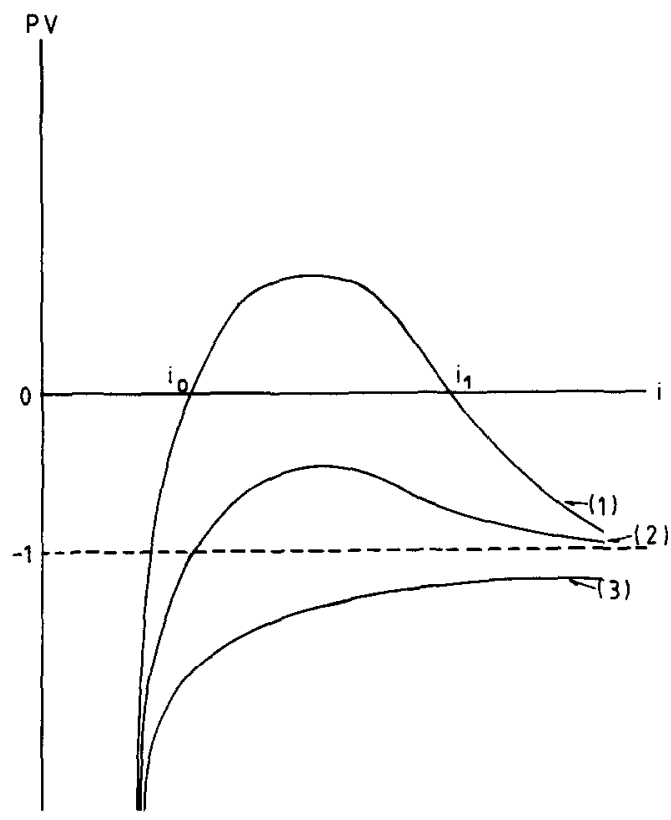

FIGURE 3

exponential rate of growth of these preservation benefits; and $\delta$, the anticipated exponential rate of decay of the real net benefits of the projected development. ${ }^{9}$ The impact of their addition, as shown in Section $I$, is to alter fundamentally the shape of the $P V$ criterion (from that of Fig. 1 toward that of Fig. 2). In fact, however, Fig. 2 illustrates only one of the possible functional relationships between $P V$ and $i$ that result from various collections of values for $D, P, \delta$, and $\rho$. In this section, we examine the "shape" of their impact more closely.

There are three kinds of functional relationships that can emerge. To see this, take the derivative of the $P V$ function, Eq. (5), with respect to $i$ :

$$
\frac{d P V}{d i}=-\frac{D}{(i+\delta)^{2}}+\frac{P}{(i-\rho)^{2}}
$$

This derivative is clearly positive if $P>D$. If, however, $D>P$, then the derivative is positive for low values ${ }^{10}$ of $i$ and negative at high values of $i$; there is, therefore, a value of $i$ which yields a maximum value of $P V$. This maximum $\left(P V^{\max }\right)$ occurs at

$$
i=\frac{\delta \sqrt{P}+\rho \sqrt{D}}{\sqrt{D}-\sqrt{P}},
$$

and is

$$
P V^{\max }=\frac{(\sqrt{D}-\sqrt{P})^{2}-(\delta+\rho)}{\delta+\rho}
$$

\footnotetext{
${ }^{9}$ The analysis, of course, still requires one traditional parameter: $D$, the current flow of real net benefits attributable to the development project.

${ }^{10}$ That is, at values above but near $\rho$.
} 


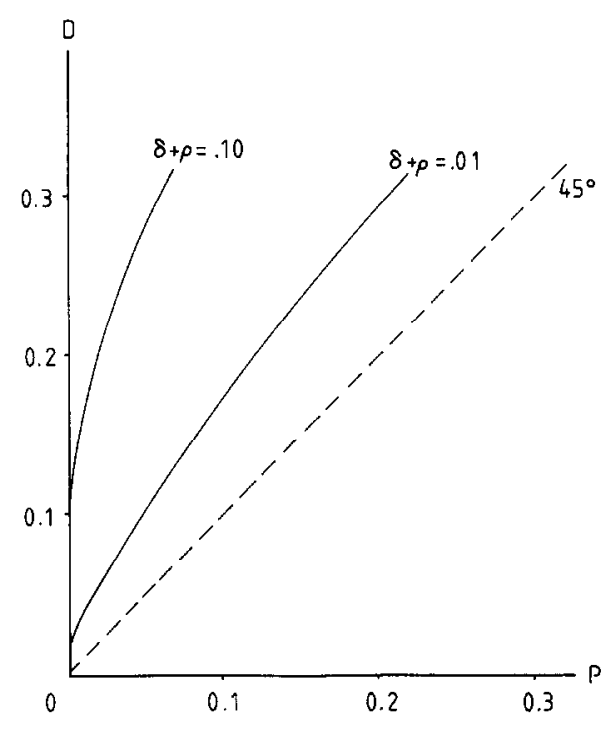

FIGURE 4

But this $P V^{\max }$ is positive only if

$$
\sqrt{D}>\sqrt{P}+\sqrt{\delta+\rho}
$$

Thus, three possible patterns of $P V$ and $i$ emerge, depending upon whether:

(1) $\sqrt{D}>\sqrt{P}+\sqrt{\delta+\rho}$;

(2) $\sqrt{P}+\sqrt{\delta+\rho}>\sqrt{D}>\sqrt{P}$; or

(3) $\sqrt{P}>\sqrt{D}$.

These are shown in Fig. 3. Only curves of type (1) ever display a positive $P V$. Thus, for a development project to pass the $P V$ test, it is necessary-but not sufficient, of course-that inequality (9) hold.

The importance of $D$ and $P$ in inequality (9) is readily comprehended by common sense; the importance of $\delta$ and $\rho$ is not. But a few numerical examples are illuminating. In Fig. 4 are drawn the critical curves showing the parameter loci at which inequality (9) is just fulfilled, at values of the sum of $(\delta+\rho)$ equal to 0.01 and 0.10 . Even if $(\delta+\rho)$ is as low as $0.01, D$ must be more than 1.5 times $P$ if a development project is to be able to pass the $P V$ test at some $i$. If $(\delta+\rho)$ is more like 0.10 , even a quite small value of $P$ is sufficient to insure that only for very large values of $D$ will a project be able to pass the $P V$ test at some $i$.

In short, consideration of current preservation benefits $(P)$ is important: these provide a sort of floor to the flow of development benefits $(D)$ needed to justify a project. But current flows of preservation benefits are seldom (measurably) large. And it is here that the rate of growth of preservation benefits $(\rho)$ and rate of decay of development benefits $(\delta)$ may enter critically to defeat seemingly profitable development projects. Small values of the sum, $(\delta+\rho)$, can be influential and small changes can be significant. ${ }^{11}$

\footnotetext{
${ }^{11}$ It should be noted that all of these results hold as long as $\delta$ is less than $\rho$. It is not strictly necessary that development benefits decay.
} 


\section{NOW OR NEVER}

The very manner in which the $P V$ test has been conceived in Sections I and II implies that the development project is a now-or-never decision. In each of Eqs. (1), (2), and (5), the $P V$ of the development now (i.e., at $t=0$ ) is computed, and the $P V \gtrless 0$ test implicitly compares the development project now with the alternative of preservation forever. While we continue to assume, until Section VI, that the wilderness disruption is irreversible, we must now consider the possibility that the development project is postponable. It is pretty obvious that postponement of a project where benefits are decaying over time is unprofitable, but exploration of the possibility yields other insights.

Consider the same development project discussed in the preceding two sections, except that it is to be implemented at time $T(T>0)$, with the preservation benefits being reaped until that time. Then the $P V$ is

$$
\begin{aligned}
P V & =-e^{-i T}+\int_{t=T}^{\infty} D e^{-(i+\delta) t} d t-\int_{t=T}^{\infty} P e^{-(i-\rho) t} d t \\
& =-e^{-i T}+\frac{D}{i+\delta} e^{-(i+\delta) T}-\frac{P}{i-\rho} e^{-(i-\rho) T}
\end{aligned}
$$

It is possible to show that there are only two kinds of loci that this $P V$ can follow over different values of $T$-those shown in Fig. 5. Take the derivative of Eq. (10) with respect to $T$ :

$$
\frac{d P V}{d T}=e^{-i T}\left[i-D e^{-\delta T}+P e^{\rho T}\right]
$$

If this is positive at $T=0$, it is clearly positive for all $T>0$, and hence the $P V$ approaches an asymptote of zero from below, as shown in part (1) of Fig. 5. On the other hand, if the derivative (11) is negative at $T=0$, it must become positive at some positive value of $T$ since its negative (middle) term is decaying more rapidly than its two positive terms as $T$ increases. Since again the $P V$ must approach zero from below in the limit as $T$ approaches infinity, the locus must cross the $T$-axis at $T_{0}$, as pictured in part (2) of Fig. 5.

The two loci displayed in Fig. 5 clearly show that development should be a now-or-never decision. In part (1), the $P V$ is at its most negative if development were to occur now and the $P V$ improves the longer it is postponed-although the decision should be to postpone forever. In part (2), the $P V$ is at its most positive now and $P V$ declines steadily until it becomes negative and stays negative-ideally, the decision is development now. All this is obvious. What is not so obvious is that, if $P V$ is positive for development now, $P V$ bécomes negative for development at some (finite) future time (i.e., at time $T_{0}$ in part (2) of Fig. 5. This latter fact has three interesting implications.

One implication is that socially profitable wilderness development must be expedited, for every moment's delay reduces the $P V$ of its profitability. ${ }^{12}$ Indeed, if

\footnotetext{
${ }^{12}$ That $P V$ falls, as viewed from $T=0$, at least until values of $T>T_{0}$, is seen in part (2) of Fig. 5. It can also be shown that the $P V$ at time $T$ of development at time $T$ falls as $T$ increases.
} 

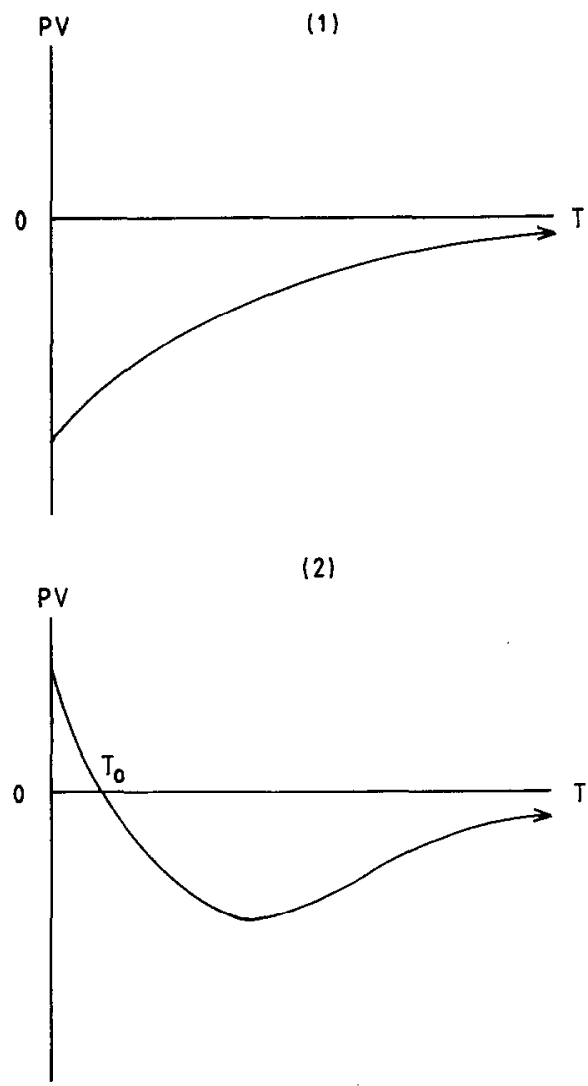

FigURE 5

the development decision is procrastinated beyond $T_{0}$, the project becomes harmful. ${ }^{13}$ A second implication is that, for obstinate preservationists, delay tactics are more than a graceless refusal to accept what is inevitable and socially profitable. If the development decision can be stalled, its apparent social profitability will decay. Indeed, a delay past $T_{0}$ will lead to a correct (at $T_{0}$ ) decision that the development ought not be undertaken. These two implications together suggest one more reason why court battles between developers and preservationists are so intense. Not only are there differences in parameter estimates to be reconciled, but the date of the decision is critical even after agreement on parameter values is achieved.

The third implication is more philosophical. We know that, if a development project is profitable now-in the sense that its $P V$ at $T=0$ is positive-it will sooner or later become unprofitable, i.e., after $T_{0}$. This means that, from the viewpoint of all generations of citizens to arrive after $T_{0}$, considered as a single group, the development is unprofitable. The decision to develop at $T=0$ is therefore an affirmation that the interests of one group, namely, the citizenry during $0<T<$ $T_{0}$, transcend the interests of the larger group of all future citizens. This result can be perceived mechanically as the inevitable result of the discounting process; and it is

\footnotetext{
${ }^{13}$ If the size of the development project is a variable, it is relatively simple to extend this framework to show that the optimal size of a profitable development diminishes over time and ultimately become zero, if preservation benefits are growing relative to development benefits [18].
} 
true that a sufficient lowering of the discount rate will always reverse the decision to develop. ${ }^{14}$ But there still nags the larger question: Can the opposing interests of this and future generations be so cavalierly reconciled as the adding up of "discounted" net benefits implies? The rationale of the dilatory tactic may well be that an irreversible development project ought not be undertaken if it is so patently not inter-generationally Pareto preferred-even though, in principle, the current generation could bribe the future generation to accept the project. ${ }^{15}$ We return to this problem in Section V.

\section{ESTIMATION OF THE PARAMETERS}

Each of the three parameters introduced by the new approach $-P, \delta$, and $\rho$-presents a far more difficult problem of estimation than does the traditional development project parameter, $D$. But for two of them at least, $\delta$ and $P$, there are standard if not entirely satisfactory procedures of estimation. For $\delta$, explicit extrapolation of the expected trends of development benefits and costs is needed. For $P$, estimation of the current consumer surplus of wilderness users is conceptually straightforward, although it is made difficult in practice by the fact that wilderness is usually underpriced [29]. It is the final parameter, $\rho$, for which the new approach has also developed a new technique of estimation.

The rate of expansion of the willingness to pay for wilderness activities in a particular area $(\rho)$ is seen, in the new approach, as a function of the rates at which the vertical and the horizontal intercept of the demand curve for that area are shifting outward. Although the linkage to consumer behavior theory is not tight, it is not unreasonable to think that the high income elasticity of the demand for wilderness activities and the continued reduction in the supply of substitutable preserved wild spaces will indeed raise both intercepts. If the shift rate of the vertical intercept is $v$ and of the horizontal intercept is $h$, and the demand curve is assumed to be linear, then the willingness to pay (equal, with the usual assumptions, to the area under the demand curve) grows at a rate of $(v+h+v h)$, or, for small values of $v$ and $h$, approximately $(v+h)$. The estimate of $\rho$ is then simply the sum of the estimates of $v$ and $h$.

There are, however, three problems. One, the estimation of $v$ and $h$ is not simple. One can extrapolate trends of visitor-days to estimate $h$ fairly confidently enough, since the horizontal intercept is the observable component of the demand curve for an unpriced facility. ${ }^{16}$ But an estimate of income elasticity is not adequate as an indication of $v$. With a higher income, a wilderness consumer would presumably visit more often as well as be willing to pay more per visit, and there is no simple way to find out how much of the income elasticity affects $h$ rather than $v$.

The second problem involves the carrying capacity of the wilderness area. If some of the demanders (at zero price) must be turned away, the rate of growth of the willingness to pay is no longer as high as $(v+h)$. Under the new approach, it is usually then estimated to be declining steadily from $(v+h)$ to just $v .^{17}$ This is

\footnotetext{
${ }^{14}$ In terms of Fig. 3, a value of $i$ below $i_{0}$ will render the development project unprofitable.

${ }^{15} \mathrm{As}$ it could as long as alternative investment projects yielding an internal rate of return of at least $i$ are available.

${ }^{16}$ In practice, travel costs must be reckoned with.

${ }^{17}$ See, for example, [25, Appendix 6-A] or [24, Appendix B]. See the Appendix for proofs of the statements of this section.
} 
correct provided that entry into the wilderness area is somehow restricted only to the highest willingness-to-pay users. ${ }^{18}$ Inasmuch as price has rarely been used, indeed contemplated, as a rationing device for public wilderness recreation, it is difficult to see how such an allocation would be achieved. It seems more likely that entry would be rationed randomly or by queue, in which case the rate of growth of preservation benefits is less rapid. In fact, if queueing is adopted as the allocation device, the net willingness to pay (i.e., in excess of the time "paid" in the queue, which is a resource cost, not a transfer) may even decline over time. In sum, once capacity is reached, the traditional techniques of rationing wilderness access do not ensure a maximum growth of total willingness to pay, and the assumption that they do will mean an overstatement of the rate of growth of wilderness benefits.

The final problem derives from the fact that the number of potential users of a particular wilderness area grows for two reasons, from a general growth in wilderness demand and from a shrinkage in the size, quality, and number of alternative wilderness areas. If the demand curve for total wilderness areas is shifting rightward (i.e., in its horizontal intercept) at rate $h$ and the total capacity of wilderness is contracting at rate $c$, then the rightward demand shift for any particular wilderness area that remains preserved becomes $(h+c)$ and the rate of growth of the total willingness-to-pay is $(v+h+c) .{ }^{19}$ This means that the estimate of $\rho$ requires estimates not only of $v$ and $h$ but also of $c$, the rate at which comparable, substitutable wilderness areas are being destroyed. Estimates of $\rho$ based only on $v$ and $h$ will be underestimates. ${ }^{20}$

Discussion of estimation techniques indicates more clearly the ultimate basis of differences between beavers and druids. The "old" parameter, $D$, was at least one on which honest, reasonable, objective analysts should have been able to agree. Estimates of willingness to pay for unpriced activities (i.e., $P$ ) and of the rate of change in the future of the development benefits (i.e., $\delta$ ) are inherently more debatable. And the rate of growth over time of wilderness demand (i.e., $\rho$ ) is an estimate to which tremendous uncertainty must irremedially adhere. Indeed, inasmuch as $\rho$ depends upon the rate at which the total wilderness capacity is contracting (i.e., $c$ ), its estimate, so critical to the new approach, is partly dependent upon the degree to which the new approach succeeds in defending wilderness from development. Despite these uncertainties and interrelationships, the claim of the new approach is that its use is preferable to the conceptually erroneous, if more easily estimated, "old" approach.

\section{DISCOUNTING}

Preservationists have always felt ambivalent about the discount rate appropriate for benefit-cost analyses involving wilderness. On the one hand, their concern for the future suggested that a very low rate of discount should be attached to future benefit streams. On the other hand, the traditional development criterion-as shown in Fig.

\footnotetext{
${ }^{18}$ Provided also that the total capacity of this and other similar (i.e., substitutable) wilderness areas is not contracting. This problem is discussed in the next paragraph.

${ }^{19}$ Declining to $v$ as time passes.

${ }^{20}$ Unless $h$ is carefully defined to be the rate of shift of demand for the particular wilderness area; then, it should be noticed, there is again an implicit general-equilibrium model lurking behind the estimate.
} 
1 and Eq. (1) - required only that $D$ be greater than $i$, and hence made more likely a decision for development the lower the discount rate used. ${ }^{2 l}$

This ambivalence is much mitigated under the new approach since projected development of wilderness areas will now fail the benefit-cost test if either a low enough or a high enough interest rate is applied-as shown in Fig. 2 and Eq. (5). Nevertheless, the controversy persists because a range of interest rates is actually observed in capital markets, because there is no consensus as to which most nearly reflects whatever it is the discount rate in benefit-cost analysis is supposed to reflect, and because the wilderness development or preservation decision so often turns critically on which discount rate is selected.

From the spectrum of observed market interest rates, economic theory focuses on two concepts: the social rate of discount (or time preference), which we hereafter refer to as $i$; and the social rate of return on investment (or opportunity cost of capital), which we hereafter refer to as $r$. It is generally agreed that the latter, $r$, exceeds the former, $i$, owing to taxation [20], the public-good attribute of saving [26], and/or the excess of private over socially optimal risk aversion [1].

One can make a case, with the stereotypical project being considered here, for using either the social time preference rate $(i)$ or the rate of return on investment $(r)$. It depends whether the resource flows (positive and negative) generated by the project represent changes in consumption or investment. The basic Eq. (5) is derived on the assumption that all the resource flows represent changes in consumption at the moment they occur. Thus, the initial investment of $\$ 1$ means a reduction in consumption of $\$ 1$ at $t=0$ and hence has a present value of $-\$ 1$. The development benefits $\left(D e^{-\delta t}\right)$ and the foregone preservation benefits $\left(P e^{\rho t}\right)$ represent changes in consumption in year $t$, and hence their present value requires multiplication by $e^{-i t}$, $i$ being the social rate of time preference (between consumption now and consumption later).

But one might just as well argue that all the resource flows represent changes in investment, only becoming a change in consumption at some very distant time, $T$. The present value of such a consumption stream is

$$
\begin{aligned}
P V & =e^{-i T}\left\{-e^{r T}+\int_{t=0}^{T} D e^{-\delta t} e^{r(T-t)} d t-\int_{t=0}^{T} P e^{\rho t} e^{r(T-t)} d t\right\} \\
& =e^{(r-i) T}\left\{-1+\frac{D}{r+\delta}-\frac{P}{r-\rho}\right\} .
\end{aligned}
$$

This present value is positive or negative according as the quantity within the brackets is positive or negative; but this is nothing else but the basic benefit-cost equation (5) with $r$ substituted for $i$ throughout.

While a case can be made for using either $i$ or $r$ in the benefit-cost analysis, only one of the cases can be empirically correct. A resource flow in fact changes either consumption or investment (or some combination of them). Unfortunately, it is not easy to know which. ${ }^{22}$ But the choice may be critical. Suppose, for example, for our

\footnotetext{
${ }^{21}$ See, for examples, [25, p. 89n.; 10, pp. 268-270; 8, pp. 159-161]. For a good summary of the more profound economic-philosophical problems with discounting where inter-generational decisions are being made, see [14, Chap. 10;33].

${ }^{22} \mathrm{See}$, for fuller discussion of this choice, $[17,7]$.
} 
stereotypical project, that we know (somehow) the initial \$1 investment means foregone investment elsewhere and all the resulting new development and lost preservation flows mean equivalent changes in consumption. The present value of this project is

$$
\begin{aligned}
P V & =\int_{t=0}^{\infty} r e^{-i t} d t+\int_{t=0}^{\infty} D e^{-(i+\delta) t} d t-\int_{t=0}^{\infty} P e^{-(i-\rho) t} d t \\
& =-\frac{r}{i}+\frac{D}{i+\delta}-\frac{P}{i-\rho}
\end{aligned}
$$

The conceptual difference between Eq. (13) and the basic equation (5) is that $r$ is no longer treated as identical to $i$. And the practical difference is that, since $r>i$, the $P V$ of the project is reduced. Recognition that the initial investment component of a project is more likely than the project's other flows to mean foregone investment elsewhere makes more stringent the test which must be passed by any investment project, including projects which would develop wild areas.

It should also be noted that this explicit introduction of $r>i$ may fundamentally alter the shape of the relationship between $P V$ and $i$. From the basic equation (5), three different shapes were possible according to the relative values of the parameters, $D, P, \delta$ and $\rho$ (as shown in Fig. 3). There, the $P V$ changed sign (as $i$ increased from $\rho$ ) either twice or not at all. With the introduction of $r$, under the assumptions that lead to Eq. (13), the $P V$ changes sign at most once. ${ }^{23}$ To the extent that the present assumptions are more typical of wilderness development projects, the last vestige of ambivalence about interest rates on the part of preservationists (mentioned at the start of this section) is removed. For sufficiently high values of $i$, a development project will be profitable provided only that its initial benefits $(D)$ exceed the initial foregone preservation benefits $(P)$ plus the opportunity cost of the initial capital required $(r)$. But at sufficiently low values of $i$, that same project will fail the benefit-cost test. The introduction of $r$ also increases the critical value of $i$ below which the development project fails. The quantitative magnitude of the changes is not small, either, as numerical examples quickly show. For example, if $D=0.25, P=0.05, \delta=0.01, \rho=0.03$, and $r=0.15$, the internal rate of return (i.e. the value of $i$ at which $P V=0$ ) is roughly $4 \%$ if one ignores $r$ (i.e., uses Eq. (5), where $r=i)^{24}$ and roughly $9 \%$ if one takes the $r$ into consideration (i.e., uses Eq. (13).

Noting that the introduction of different values for $r$ and $i$ may critically affect wilderness decisions is one thing. One has still to decide which resource flows ultimately alter consumption and which investment, no easy task. But the most difficult job of all is to locate the correct values of these discount rates. Theory is of little use, partly because it is based on such idealized assumptions as perfect foresight and complete futures markets, and partly because it assumes that capital markets clear at a single interest rate, so that $r=i$. For what little it is worth, however, the counsel of economic theory is that optimal saving and investment paths

\footnotetext{
${ }^{23}$ Set the $P V$ equation (13) equal to zero, multiply through by $i(i+\delta)(i-\rho)$, and transform the variable to $(i-\rho)$, getting $(i-\rho)^{2}(D-r-P)+(i-\rho)(\ldots)-\rho(\delta+\rho) P=0$. Provided that $D>$ $r+P$, this quadratic in $(i-\rho)$ has one positive real root regardless of the sign of the middle term (abbreviated to three dots above)

${ }^{24} 4 \%$ is the lower internal rate of return (i.e., $i_{0}$ of curve (1) of Fig. 3).
} 
probably imply low rates of interest, equal to such things as (1) the natural rate of growth (of "effective" labor) of the economy, (2) this growth rate times the (absolute value of the) elasticity of the marginal utility of consumption with respect to consumption, or (3) this product of growth rate and elasticity plus a "utility discount factor." 25 Such mean clues are further depreciated by difficulty of quantification, even intuitively, of the concepts, elasticity of marginal utility and the utility discount factor. ${ }^{26}$

But information about some hypothetical or efficient market-clearing interest rate is, in any case, of little use to the quester "in the dark jungles of the second best" [5, p. 789]. Where different interest rates are relevant, they must be recognized and estimated. Wilderness benefit-cost analysis cannot consider less than two interest rate concepts. One, the opportunity cost of capital $(r)$, is eminently estimable, in principle and in fact. It is simply the (pre-tax) value of the productivity of the relevant marginal investments of the economy. ${ }^{27}$ The difficult estimate, in principle and in fact, is of the social rate of time preference $(i)$. It must be used whenever society contemplates altering consumption, as opposed to investment, across time. But the greater ease of conceptualization and estimation of $r$, relative to $i$, has led some economists to recommend the rejection of $i$ as a relevant ingredient in benefit-cost analysis. ${ }^{28}$

Others offer a more sophisticated rationale for concentrating on the opportunity cost of capital $(r)$ as the discount factor throughout a benefit-cost analysis. If opportunities exist for investment at rate $r$, then future generations can always be made better off if development projects are pursued that pass the benefit-cost test when discounted at rate $r$. Reference to Eq. (12) makes this clear. Insistence by the preservationist on the continued inclusion in the analysis of some rate $i$, below $r$, rests on one (or both) of two beliefs. One, the bribe necessary to induce "the future" to accept a development project may require that "the present" save and invest a large portion not only of the returns to the wilderness development project but also of the returns to the previously invested returns. ${ }^{29}$ The use of a low value of $i$ in place of $r$ may simply reflect a lack of trust, on the part of the preservationist, that this great debt to the future will be honored through sufficiently high saving rates, especially as the net benefits received from the development project dwindle exponentially. There may be, in short, a conflict between what is potentially Pareto

\footnotetext{
${ }^{25}$ For a brief tour through the theory, see $[30,1,32]$. The received theory also shows that the competitive market solution, despite the absence of all the usual sources of inefficiency, may be inefficient; see, for example, [15].

${ }^{26}$ Nor is the empirical evidence about time preference sufficiently focused to be of much help. Some people lend their wealth at near-zero real rates of interest, while others borrow-even in advanced countries with supposedly developed capital markets-at rates of $20 \%-50 \%$. Micro studies have estimated private time preference at rates as high as $33 \%[1$, p. 18]; and macro studies have estimated social time preference at rates as low as 1\% [27].

${ }^{27}$ Relevant in the opportunity-cost sense of the investments that will actually be foregone if the wilderness development project is embarked upon.

${ }^{28}$ For example, [28]: "Since the collective private rate of time preference does not provide a basis for determining a social rate of discount, the only observed rates available for use as a guide for the evaluation of public projects is $[$ sic] the rate of return on private capital or the opportunity cost of private capital." (p. 38)

${ }^{29}$ In the stereotypical project, the development project can increase consumption at all $t$ only if, in addition to passing the test of Eq. (12), at least a fraction, $\rho / r$, of all returns $\left(D_{t}\right)$ are invested (and reinvested) at rate $r$.
} 
preferred and what will probably eventuate, and the low $i$ is a means of giving weight to this probability. ${ }^{30}$ The second belief, on which the insistence on the use of a low $i$ may rest, is that with each wilderness development, the options of future generations are being irreversibly reduced. Our uncertainty about the rate of growth of the costs of these lost options makes our current estimate, $\rho$, a highly inadequate parameter for a benefit-cost analysis which ignores uncertainty. One long-honored, if much debated, way out of this uncertainty dilemma is the use of a risk-premium in the discount factor itself. ${ }^{31}$ The gap between $r$ and $i$ may reflect the preservationist's feeling of uncertainty about the evaluation of wilderness by future generations.

Whichever the rationale, the wilderness preservationist should urge that two different discount rates ( $r$ and $i$ ) be used in assessing a potential development project, depending upon whether investment or consumption flows are affected. This dichotomization of the discount factor can make a critical difference in the evaluation of wilderness development projects. To see this, consider our stereotypical wilderness destruction-cum-development project along side of a stereotypical "industrial" project-a project without environmental implications that promises a perpetual flow of net benefits at a rate of $\$ x$ at an investment cost today of $\$ 1$. The present value of the industrial project, assuming the initial $\$ 1$ to be diverted from investible funds elsewhere and the $\$ x$ flow to go entirely to consumption, is simply

$$
P V=-\frac{r}{i}+\frac{x}{i}
$$

This industrial project should be undertaken if $x>r$. Note that the value of $i$ is irrelevant to the decision. ${ }^{32}$

While the value of $i$ makes no difference to the evaluation of the "industrial" project, it does make a difference to the evaluation of the wilderness project-as inspection of Eq. (13) makes clear. Indeed, there is a locus of values of $r$ and $i$ which makes the $P V$ of the wilderness project exactly zero, $P V$ being positive on one side and negative on the other side of that locus. This locus may be found by setting the $P V$ of Eq. (13) equal to zero and solving for $r$ in terms of (the various other parameters and) $i$ :

$$
r=\frac{i}{i+\delta} D-\frac{i}{i-\rho} P
$$

The break-even locus of the wilderness project (i.e., Eq. (15)) and the break-even locus of the industrial project (i.e., $x=r$ from Eq. (14)) are both plotted in Fig. 6. Four regions are thereby demarcated, and the effective roles of each of the parameters, $r$ and $i$, can be seen. Higher values of $r$ make fewer projects profitable-a reasonable result since higher values of $r$ mean that high-productivity alternative investments are available. But higher values of $i$ make only the wilderness development projects more profitable. Again, a reasonable result, since higher values of $i$ mean that society values near-future consumption $\left(D_{t}\right)$ more than distant-future

\footnotetext{
${ }^{30}$ It is, of course, not the only way. Baumol [5] has suggested that "a set of selective subsidies" (p. 801) is preferable. The advantage of a low $i$ is that it does not need to be haggled, ad hoc, for each project.

${ }^{31} \mathrm{Sec}$, for example, [16, pp. 86ff].

${ }^{32}$ One could just as well ignore $i$ in this $P V$ equation, using $r$ throughout as the discount factor. Then, $P V=-1+x / r$, which also yields $P V>0$ if $x>r$.
} 


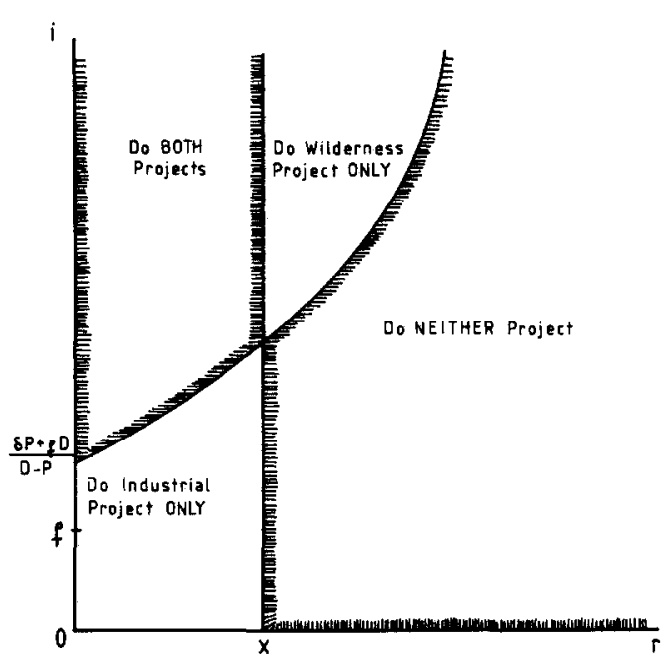

FigURE 6

consumption $\left(P_{t}\right)$. Those who would protect wilderness through benefit-cost analyses want both realistic values of $r$ and low values of $i$.

Before leaving Fig. 6, we should notice that the use of a low value of $i$ is not "a Robin Hood activity stood on its head" [5, p. 800]. It is low values of $r$ that lead to more investment projects being accepted and hence a redistribution from (current) poor to (future) rich generations. A lower value of $i$, ceteris paribus, can only reduce the total number of projects accepted by reducing the number of wilderness development projects undertaken.

How low should $i$ be? We return to the basic problem. Neither theory nor evidence provides much insight. One can use introspection. Consider a willingnessto-pay a century from now of $\$ 1$ (in today's prices) to see the Grand Canyon; how much is that worth today? At an $i$ as high as $5 \%$, it is $\$ 0.0067$, less than one penny. Even at an $i$ of $3 \%$, it is only $\$ 0.0498$, less than a nickel. It is unfortunate that wilderness preservation must turn on so personal and debatable a parameter, but there may be no escape.

\section{REVERSIBILITY}

So far we have been assuming, as does most of the preservationist literature, that any wilderness development project is forever irreversible. In many cases this is quite reasonable, unless one takes a geologist's view of time. For example, flooding the Grand Canyon, damming Hetch Hetchy, or logging the redwoods are for all practical purposes irreversible acts. For other wilderness areas and for other development activities, the process is reversible in the simple sense that reasonable amounts of time and resources are sufficient to restore wilderness values.

The fact that the development benefits $\left(D e^{-\delta t}\right)$ are high for the near future and that the wilderness benefits $\left(P e^{p t}\right)$ become high later on suggests that, if reversibility is possible, a sequence of development followed by wilderness restoration should be considered. This change in tactic means that the entire task of the wilderness 
advocate changes. It is necessary to determine two things: (1) whether the development project should be undertaken, and (2) whether (and when) the area should be reconverted to wilderness. Mathematically, the $P V$ formula becomes somewhat more complex. The development benefits are earned and the wilderness benefits foregone only until time $T$, when reconversion occurs; and the net cost of reconversion $(R)$ must be introduced: ${ }^{33}$

$$
\begin{aligned}
P V & =-1+\int_{t=0}^{T} D e^{-(i+\delta) t} d t-\int_{t=0}^{T} P e^{-(i-\rho) t} d t-R e^{-i T} \\
& =-1+\frac{D}{i+\delta}\left[1-e^{-(i+\delta) T}\right]-\frac{P}{i-\rho}\left[1-e^{-(i-\rho) T}\right]-\operatorname{Re}^{-i T}
\end{aligned}
$$

Analysis of this $P V$ must occur in two stages. First, the optimal reconversion date, $T$, must be calculated (i.e., where $d P V / d T=0$; note that $d^{2} P V / d T^{2}<0$ there). Then, for the optimal value of $T$, the $P V$ of the entire project must be evaluated. The new term of Eq. (16), the one that involves $R$, plays a role in both these evaluations. Higher (net) restoration costs push further into the future the time at which the restoration of the wilderness should occur, but they also make it less likely that development should occur at all. Explicit consideration of the possibility of reversibility means that the choice is no longer between $T=0$ and $T=\infty$. The problem of now or never, discussed in Section III, need not arise. Indeed, a solution that is more nearly Pareto optimal between generations may present itself. The current generation may reap the benefits of development of the area, and later generations nevertheless enjoy the restored wilderness.

Several practical problems arise for the wilderness preservationist, or rather in this case the wilderness reservationist. At the time of the development (i.e., at $t=0$ ), it is essential that there be formal commitment that the area is reserved for ultimate status as wilderness. In principle, this presents no problem provided we have been correct in our assessment that the development benefits are decaying, but there is always the danger that the first development will be quietly succeeded by a second, different project without a new social benefit-cost test. It is at once too much and not enough that the date of restoration $(T)$ be fixed definitely. Circumstances, uncertain now, may arise that require the date of restoration to be postponed; in other circumstances, the development project may exhaust itself unexpectedly early and the quiet successor must be alertly avoided. The final problem concerns the liability for reconversion costs. For social efficiency, it is irrelevant as long as the development decision and the reversion date are correctly decided. But in practice, this may be the most difficult issue.

\section{POSTPONABILITY}

So far we have been assuming that the development project under consideration is inexhaustible-in the sense that its net benefits go on forever, albeit at a declining rate over time. ${ }^{34}$ Under such a circumstance, the question of postponement is

\footnotetext{
${ }^{33} \mathrm{By}$ net cost is meant the restoration costs minus the salvage value of the installed development capital at time $T$; this net cost is generally much larger than mere "interment" costs [23, p. 379]. I assume, for simplicity, that restoration occurs instantaneously at $T$, and I ignore any difference between $r$ and $i$.

${ }^{34}$ If the cause of the declining rate of net benefit flow is rising real extraction costs, one might call this a situation of asymptotic exhaustibility.
} 
irrelevant; as was shown in Section III, an irreversible, inexhaustible development project should be undertaken now or never. We now consider an irreversible but exhaustible development project, i.e., one in which the net benefit flow ceases within a finite period, but the preservation benefits are nevertheless lost forever. ${ }^{35}$ Examples of such projects are not rare: petroleum extraction that leads to the extinction of species or strip mining that scars a wilderness almost irreversibly from the view of reconversion cost and time. For such exhaustible development projects, it can be shown that postponement may be a socially profitable decision. ${ }^{36}$

Consider, for simplicity, not the development project we have been consideringthat lasts forever-but rather a development project of the extreme opposite character - that yields all its costs and benefits at a single moment of time $(T)$. Thus, at time $T$, the development project would cost $\$ 1$ in initial investment and yield $D e^{\alpha T}$ in net benefit, where $D$ is the net benefit the project would offer if it were undertaken now (i.e., at $T=0$ ), and $\alpha$ is the rate of appreciation of the value of the project's output. The rate of appreciation might be negative (as earlier for $\delta$ ), but it is obvious that the project then is a now-or-never decision since its (momentary) benefits decline as time passes while its investment cost and preservation opportunity cost do not. But there are many extracted resources whose prices are expected to rise over time. The $P V$ of development at time $T$ is $^{37}$

$$
\begin{aligned}
P V & =-e^{-i T}+D e^{-(i-\alpha) T}-\int_{t=T}^{\infty} P e^{-(i-\rho) t} d t, \\
& =e^{-i T}\left\{-1+D e^{\alpha T}-\frac{P e^{\rho T}}{i-\rho}\right\}
\end{aligned}
$$

where the final term reflects the benefits of the continued wilderness use until time $T$.

There is no current controversy about postponement unless the development project passes its $P V$ test now; whenever it does, it means that the $P V$ at $T=0$ in Eq. (17) is positive, i.e.,

$$
-1+D-\frac{P}{i-\rho}>0
$$

This project, although profitable now, should be postponed if its $P V$ rises over time. Take the derivative of Eq. (17) with respect to $T$ and evaluate it at $T=0$ :

$$
\left.\frac{d P V}{d T}\right|_{T=0}=i-(i-\alpha) D+P
$$

This must be negative or the project will become more valuable (in a $P V$ sense) in the future than it is now. And in this latter case, it should be postponed despite its current profitability. Inspection of (18) and (19) indicates that the lower the value of $i$ or the higher the value of $\alpha$, the more likely it is that the project will fail at least one of these tests.

\footnotetext{
${ }^{35}$ Reversible, exhaustible development projects provide similar problems of analysis and are not examined here.

${ }^{36}$ See, for an example of such a project, [6].

${ }^{37}$ Ignoring any difference between $r$ and $i$ throughout.
} 
The new approach to wilderness preservation must examine exhaustible development projects from two viewpoints. Such projects, if they are to be sensibly undertaken now, must prove to be (1) socially profitable now and (2) not even more profitable later. If either test is failed, the wilderness should be preserved, at least for the time being.

\section{SUMMARY}

The intent of this paper has been to provide an exposition of the kinds of changes of benefit-cost technique the new approach demands and of the kinds of changes in results that may ensue. It should be noted once more that the reliance throughout, for simplicity, on a "stereotypical project" of wilderness development means that many of the results are not necessarily generalizable and are certainly not quantitatively meaningful. ${ }^{38}$ Qualitative changes in wilderness benefit-cost techniques and results, brought on through the new approach, are many and dramatic. The principal changes (numbered by the section of the paper in which they are derived):

1. Explicit introduction of a measure of the wilderness values foregone through development means that the shape of the decision process is dramatically altered. Development projects may fail their benefit-cost tests not only because the discount rate is too high but also because it is too low.

2. Not only are both the current flows of net benefits from wilderness development and preservation (i.e., $D$ and $P$ ) critical to the benefit-cost analysis, but also the rates of change over time of these benefits (i.e., $\delta$ and $\rho$ ) are important.

3. Wilderness development projects, if they are socially profitable at all, are probably most profitable now. Delay generally reduces their profitability, which fact raises tough questions of inter-generational equity.

4. Measuring the time-flow of benefits of preserved wilderness, as the new approach requires, is no easy task-especially difficult is the rate of growth in the future of people's willingness to pay for wilderness activities. The new approach has sharpened the conceptual basis of these estimates.

5. In a world where multiple interest rates are observed, the necessarily second-best analysis of wilderness development projects must utilize at least two discounting concepts. The rate of return to investment $(r)$ may be sufficient for assessing "industrial" projects, but the rate of social time preference $(i)$ is also needed for assessing wilderness projects.

6. Where the development project is reversible-i.e., the wilderness restorablethe benefit-cost test must also determine the date at which (and if) reversion to wilderness should occur.

7. Where an exhaustible development project is being considered, the benefit-cost test must also determine the date at which the exploitation should begin-even if socially profitable now, the development project may nevertheless be profitably postponed.

\section{APPENDIX}

The rate at which the total willingness to pay $(T W P)$ for wilderness activity grows depends upon the means by which it is rationed. In this appendix the formulas are

\footnotetext{
${ }^{38}$ In practice, for example, neither $D_{t}$ nor $P_{t}$ are likely to involve smooth exponential trends.
} 
derived for $T W P$ and its growth rate under three different rationing systems: (i) the highest willingness-to-pay demanders gain entry; (ii) entry is permitted at random among all positive willingness-to-pay demanders; and (iii) entry is restricted by queue. The principal results are that (i) the first of these three rationing systems displays the highest level and growth rate of TWP; (ii) the third of the three rationing systems displays the lowest level and growth rate of $T W P$; and (iii) in no case is the growth rate of TWP closely approximated by the simple sum of the rates of shift of the vertical and horizontal intercepts of the demand curve.

Consider a system of wilderness areas the demand curve for which is shifting upward and outward over time and the supply of which is contracting over time. Assume for simplicity that the demand curve is linear; by suitable choice of units, let 1 be both the maximum willingness-to-pay $(w)$ of any user at time zero $(t=0)$ and the maximum flow of users $(q)$ that would enter at zero price at time zero (see Fig. A-1). We start the analysis at the moment when the carrying capacity of the wilderness system is just adequate to permit entry to all demanders who display a positive value of $w$. As time passes, the vertical intercept of the willingness-to-pay curve shifts up at rate $v$; the horizontal intercept shifts out at rate $h$; and the capacity of the wilderness shrinks at rate $c$. Figure A-1 shows the demand and supply (capacity) curves at time 0 and $t$.

If a competitive market were to allocate wilderness access, a price would appear at time zero and would rise over time (to $e^{v T}\left[1-e^{-(h+c) t}\right]$ at time $t$, as shown in Fig. A-1). Such a price would effectively restrict the use of the wilderness capacity $\left(e^{-c r}\right)$ to only the highest willingness-to-pay demanders out of the total potential demand $\left(e^{h t}\right)$. Markets are, however, not currently used to allocate wilderness use among competing applicants. We consider three rationing systems.

1. The highest willingness-to-pay demanders gain entry. At time $t$, entry is somehow apportioned just as a market would, so that all actual users are willing to pay between $\left(e^{v t}\right)$ and $e^{v t}\left[1-e^{-(h+c) t}\right]$. Because the demand curve is assumed linear,

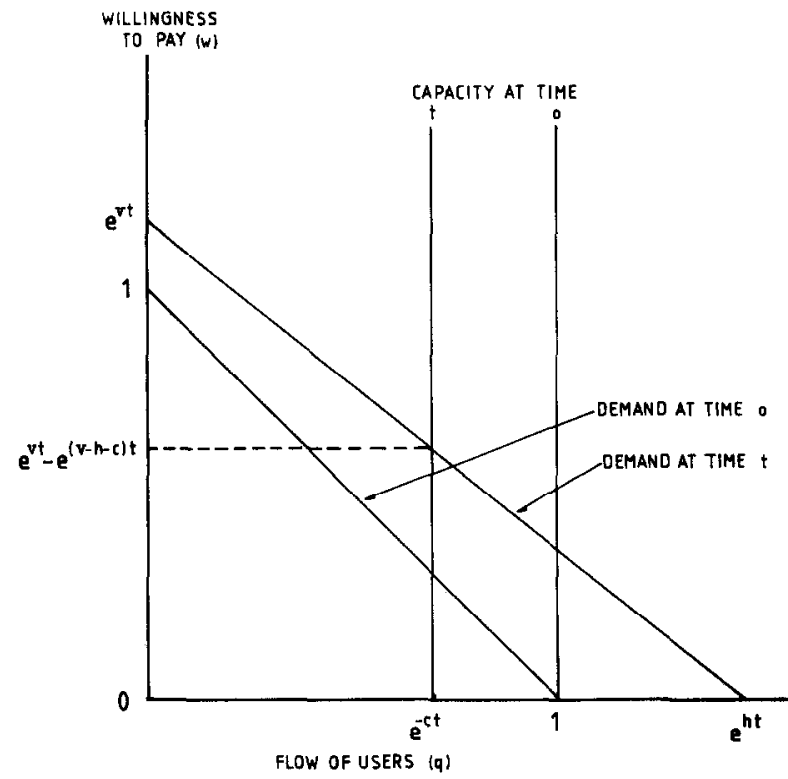

FIGURE Al 
the average $T W P$ per unit of wilderness is half-way between the high and low values:

$$
T W P=e^{v t}\left[1-\frac{1}{2} e^{-(h+c) t}\right] .
$$

And the rate of growth is

$$
\frac{d T W P / d t}{T W P}=\frac{v-\frac{1}{2}(v-h-c) e^{-(h+c) t}}{1-\frac{1}{2} e^{-(h+c) t}}
$$

It should be noted that this growth rate, the equivalent of the $\rho$ of the text, is not a constant over time. It is $(v+h+c)$ at time zero and declines to $(v)$ as time goes to infinity. Thus, ultimately only the vertical-intercept shift matters for $\rho$, but in the near future, $\rho$ is the sum of all three rates - i.e., the rate of vertical shift of the demand curve, the rate of horizontal shift of the demand curve, and the (absolute value of the) rate of contraction of total wilderness capacity.

2. Entry is permitted at random among all positive willingness-to-pay demanders. At time $t$, entry is permitted for a random collection of users whose willingness-to-pay ranges from zero to $\left(e^{v t}\right)$. With a linear demand curve, this means that the average $T W P$ per unit of wilderness left is exactly half-way between these values:

$$
T W P=\frac{1}{2} e^{v t} .
$$

And the rate of growth is

$$
\frac{d T W P / d t}{T W P}=v
$$

Both the level (at any time $t$ ) and the growth rate of the TWP are lower than under the previous system, whereby only the highest valued willingness-to-pay demanders gained access. It should be noted that, under random entry, neither the rate of horizontal shift of the demand curve $(h)$ nor the rate of shrinkage of the total wilderness area (c) affects the rate of growth of $T W P$ (i.e., of the $\rho$ used in the text).

3. Entry is restricted by queue. Assuming for simplicity that the queue is literally a line of potential wilderness users at the ranger station, we would find that line lengthening until the prospect of lost time was just sufficient to discourage a fraction, $\left(1-e^{-(h+c) t}\right)$, of the potential demanders from seeking admission. The TWP of the actual wilderness depends on the length of the queue, who is admitted, and the value of their time. Consider the simple case where the value of time is the same for all potential demanders. Then the queue will lengthen until the time wasted is exactly equal (in value) to $\left(e^{v t}\left[1-e^{-(h+c) t}\right]\right)$, and the willingness to pay of the actual users will be the excess of their willingness to pay $(w)$ above this value of wasted time. This will range smoothly from zero to $e^{(v-h-r) t}$, and hence the average $T W P$ per unit of wilderness left will be

$$
T W P=\frac{1}{2} e^{(v-h-c) t}
$$

And the rate of growth is

$$
\frac{d T W P / d t}{T W P}=v-h-c
$$


Both the level and the growth rate of this TWP are the lowest of the three rationing systems. Indeed, the growth rate in (A-6) may even be negative. For a variety of plausible growth rates (i.e., of $v, h$, and $c$ ) of demand and supply, the lengthening of the queue may erode all or more than all of the potential gains in $T W P$.

\section{REFERENCES}

1. K. J. Arrow, Discounting and public investment criteria, in "Water Resources Research" (A. V. Kneese and S. C. Smith, Eds.), John Hopkins Univ. Press, Baltimore (1966).

2. K. J. Arrow and A. C. Fisher, Environmental preservation, uncertainty and irreversibility, Quart. $J$. Econ. (May 1974).

3. K. J. Arrow and M. Kurz, Optimal growth with irreversible investment in a Ramsey model, Econometrica (Mar. 1970).

4. K. J. Arrow and R. C. Lind, Uncertainty and the evaluation of public investment decisions, Amer. Econ. Rev. (June 1970).

5. W. J. Baumol, On the social rate of discount, Amer. Econ. Rev. (September 1968).

6. R. C. Bishop and G. G. Stevenson, Endangered species and public decisions: The safe minimum standard approach, mimeo (1977).

7. D. F. Bradford, Constraints on government investment opportunities and the choice of discount rate, Amer. Econ. Rev. (December 1975).

8. D. F. Bradford and H. A. Feiveson, Benefits and costs, winners and losers, in "Boundaries of Analysis: An Inquiry into the Tocks Island Dam Controversy, (H. A. Feiveson, F. W. Sinden, and R. H. Socolow, Eds.), Ballinger, Cambridge (1976).

9. S. A. Cain, Ecological islands as natural laboratories, in "The Meaning of Wilderness to Science" (D. Brower, Ed.). Proceedings, Sixth Biennial Wilderness Conference, Sierra Club (1960).

10. A. Carlin, The Grand Canyon controversy, or How reclamation justifies the unjustifiable, reprinted in "Pollution, Resources and the Environment" (A. C. Enthoven and A. M. Freeman III, Eds.), Norton, New York (1973).

11. C. J. Cicchetti and A. M. Freeman, Option demand and consumer surplus, Quart. J. Econ. (Aug. 1971).

12. C. J. Cicchetti and V. K. Smith, Congestion, quality deterioration and optimal use: Wilderness recreation in the Spanish peaks primitive area, Social Sci. Res. (1973).

13. P. Dasgupta, S. Marglin, and A. K. Sen, "Guidelines for Project Evaluation," UNIDO, New York (1972).

14. P. S. Dasgupta and G. M. Heal, "Economic Theory and Exhaustible Resources," Cambridge Univ. Press, London (1979).

15. P. A. Diamond, National debt in a neoclassical growth model, Amer. Econ. Rev. (December 1965).

16. O. Eckstein, "Water-Resource Development: The Economics of Project Evaluation," Harvard Univ. Press, New York (1958).

17. M. S. Feldstein, The inadequacy of weighted discount rates, in "Cost-Benefit Analysis," (R. Layard, Ed.), Penguin, London (1972).

18. A. C. Fisher and J. V. Krutilla, Resource conservation, environmental preservation, and the rate of discount, Quart. J. Econ. (August 1975).

19. A. C. Fisher, J. V. Krutilla, and C. J. Cicchetti, The economics of environmental preservation: A theoretical and empirical analysis, Amer. Econ. Rev. (September 1972).

20. A. Harberger, Statement in "Hearings Before the Subcommittee on Economy in Government of the Joint Economic Committee of the Congress of the United States, July 30-August 1, 1968," Washington, D.C. (1968).

21. J. V. Krutilla, Conservation reconsidered, Amer. Econ. Rev. (September 1967).

22. J. V. Krutilla, "Natural Environments: Studies in Theoretical and Applied Analysis," Johns Hopkins Univ. Press, Baltimore (1972).

23. J. V. Krutilla, The use of economics in project evaluation, in "Transactions of the 40th North American Wildlife and Natural Resources Conference, 1975," Wildlife Management Institute (1976).

24. J. V. Krutilla, and C. J. Cicchetti, Evaluating benefits of environmental resources with special application to Hells Canyon, Natural Resources J. (January 1972). 
25. J. V. Krutilla, and A. C. Fisher, "The Economics of Natural Environments," Johns Hopkins Univ. Press, Baltimore (1975).

26. S. A. Marglin, The social rate of discount and the optimal rate of investment, Quart J. Econ. (February 1963).

27. K. Mera, An empirical determination of a dynamic utility function, Rev. Econ. Statist. (February 1968).

28. R. F. Mikesell, "The Rate of Discount for Evaluating Public Projects," American Enterprise Institute, Studies in Economic Policy (1977).

29. R. C. Porter, On the optimal size of underpriced facilities, Amer, Econ. Rev. (September 1977).

30. F. Ramsey, A mathematical theory of saving, Econ. J., (December 1928).

31. V. K. Smith, The incidence of technological progress on different uses of environmental resources, in "Natural Environments: Studies in Theoretical and Applied Analysis" (J. V. Krutilla, Ed.), Johns Hopkins Univ. Press, Baltimore (1972).

32. R. M. Solow, "Growth Theory," Oxford Univ. Press, New York/London (1970).

33. R. M. Solow, Intergenerational equity and exhaustible resources, Rev. Econ. Studies (1974).

Statement of ownership, management and circulation required by the Act of October 23, 1962, Section 4369, Title 39, United States Code; of

\section{JOURNAL OF ENVIRONMENTAL, ECONOMICS AND MANAGEMENT}

Published Quarterly by Academic Press, Inc., 111 Fifth Avenue, New York, N.Y. 10003.

Number of issues published annually: 4. Editors: Allen V. Kneese, Resources for the Future, Inc., 1755 Massachusetts Ave., N.W., Washington, D.C. 20036 and Ralph C. d'Arge, Dept. of Economics, University of Wyoming, Laramie. Wyoming 82070.

Owned by Academic Press, Inc., 111 Fifth Avenue, New York, N.Y. 10003.

Known bondholders, mortgagees, and other security holders owning or holding 1 percent or more of total amount of bonds, mortgages, and other securities: None.

Paragraphs 2 and 3 include, in cases where the stockholder or security holder appears upon the books of the company as trustee or in any other fiduciary relation, the name of the person or corporation for whom such trustee is acting, also the statements in the two paragraphs show the affiant's full knowledge and belief as to the circumstances and conditions under which stockholders and security holders who do not appear upon the books of the company as trustees, hold stock and securities in a capacity other than that of a bona fide owner. Names and addresses of individuals who are stockholders of a corporation which itself is a stockholder or holder of bonds, mortgages or other securities of the publishing corporation have been included in paragraphs 2 and 3 when the interests of such individuals are equivalent to 1 percent or more of the total amount of the stock or securities of the publishing corporation.

Total no. copies printed: average no. copies each issue during preceding 12 months: 1612 ; single issue nearest to filing date: 1653. Paid circulation (a) to term subscribers by mail, carrier delivery or by other means: average no. copies each issue during preceding 12 months: 1134; single issue nearest to filing date: 1219. (b) Sales through agents, news dealers, or otherwise: average no. copies each issue during preceding 12 months: 0 ; single issue nearest to filing date: 0 . Free distribution by mail, carrier delivery, or by other means: average no. copies each issue during preceding 12 months: 49; single issue nearest to filing date: 49. Total no. of copies distributed: average no. copies each issue during preceding 12 months: 1183 ; single issue nearest to filing date: 1268 .

(Signed) Roselle Coviello, Senior Vice President 